\title{
Paleointensity data from Early Cretaceous Ponta Grossa dikes (Brazil) using a multisample method
}

\author{
Daniele Brandt, Gelvam A. Hartmann, Elder Yokoyama, Edgard L. Catelani, and Ricardo I. F. Trindade* \\ Departamento de Geofísica, Instituto de Astronomia, Geofísica e Ciências Atmosféricas, Universidade de São Paulo, \\ Rua do Matão 1226, 05508-090, São Paulo, SP, Brazil \\ (Received October 10, 2007; Revised March 27, 2008; Accepted April 3, 2008; Online published January 23, 2009)
}

\begin{abstract}
Definition of the long-term variation of the geomagnetic virtual dipole moment requires more reliable paleointensity results. Here, we applied a multisample protocol to the study of the $130.5 \mathrm{Ma}$ Ponta Grossa basaltic dikes (southern Brazil) that carry a very stable dual-polarity magnetic component. The magnetic stability of the samples was checked using thermomagnetic curves and by monitoring the magnetic susceptibility evolution through the paleointensity experiments. Twelve sites containing the least alterable samples were chosen for the paleointensity measurements. Although these rocks failed stepwise double-heating experiments, they yielded coherent results in the multisample method for all sites but one. The coherent sites show low to moderate field intensities between $5.7 \pm 0.2$ and $26.4 \pm 0.7 \mu \mathrm{T}$ (average 13.4 $\pm 1.9 \mu \mathrm{T}$ ). Virtual dipole moments for these sites range from $1.3 \pm 0.04$ to $6.0 \pm 0.2 \times 10^{22} \mathrm{~A} \mathrm{~m}^{2}$ (average $2.9 \pm 0.5 \times 10^{22} \mathrm{~A} \mathrm{~m}^{2}$ ). Our results agree with the tendency for low dipole moments during the Early Cretaceous, immediately prior to the Cretaceous Normal Superchron (CNS). The available paleointensity database shows a strong variability of the field between 80 and 160 Ma. There seems to be no firm evidence for a Mesozoic Dipole Low, but a long-term tendency does emerge from the data with the highest dipole moments occurring at the middle of the CNS.
\end{abstract}

Key words: Mesozoic Dipole Low, Cretaceous, paleointensity, Paraná basin.

\section{Introduction}

Almost two decades ago, Michel Prévot and colleagues pointed to the existence of a long-lasting Mesozoic Dipole Low (MDL) during which the average strength of Earth's magnetic dipole was about one third that of the presentday field (Prévot et al., 1990). Although interest in paleointensity has been increasing in recent years, the existence of this MDL and other primary features of the long-term virtual dipole moment variation are still a matter of debate (e.g., Selkin and Tauxe, 2000; Goguitchaichvili et al., 2002; Heller et al., 2002; Biggin and Thomas, 2003; Tauxe, 2006; Tarduno et al., 2006).

Conflicting interpretations of currently available paleointensity data arise in part from the very limited number of entries in the paleointensity database (see Perrin and Schnepp, 2004). Classical double-heating techniques, known as the Thellier-Thellier method (Thellier and Thellier, 1959), involve stepwise heatings with alternate in-field and zero-field measurements as well as intermediate checking-steps to access the degree of alteration and the domain-structure of magnetic carriers (e.g., Coe et al., 1978; Riisager and Riisager, 2001; Tauxe and Staudigel, 2004). The ThellierThellier method is very time-consuming and can be applied only to a limited number of targets. Suitable samples

${ }^{*}$ Ricardo I. F. Trinadade is a CNPq Research Fellow.

Copyright (c) The Society of Geomagnetism and Earth, Planetary and Space Sciences (SGEPSS); The Seismological Society of Japan; The Volcanological Society of Japan; The Geodetic Society of Japan; The Japanese Society for Planetary Sciences; TERRAPUB. must have a thermoremanent magnetization, acquired during rapid cooling and carried by single-domain magnetic particles; alterations during the several laboratory heating steps should also be negligible (e.g., Coe et al., 1978). One way to circumvent the difficulties associated with this method is to look for specific targets that enclose singledomain magnetite grains and are less affected by thermochemical alteration, such as basaltic glasses (Tauxe, 2006) or single silicate crystals (Tarduno et al., 2006). An alternative approach is the use of multisample protocols (e.g., Hoffman and Biggin, 2005; Dekkers and Bönhel, 2006) that require significantly fewer heatings per sample than the stepwise double-heating techniques and, therefore, can be successfully applied to a broader class of targets.

We have applied a multisample protocol to recover the paleofield at $130.5 \mathrm{Ma}$ from the Ponta Grossa basaltic dikes. Although these basaltic rocks failed stepwise doubleheating experiments, they yielded coherent results for most of the analyzed sites when the multisample method was used. Based on our results, together with data from literature, we discuss the evolution of the Earth's field strength in the Late Mesozoic.

\section{Geological Setting and Previous Studies}

The Paraná-Etendeka Magmatic Province (PEMP) is one of the largest known continental flood volcanic province (Fig. 1). It comprises about $1.5 \times 10^{6} \mathrm{~km}^{3}$ of volcanic and subvolcanic rocks, with the majority being tholeiitic basalts and andesites with subordinate rhyolites and rhyodacites, which cover an area of around $1.2 \times 10^{6} \mathrm{~km}^{2}$. This 


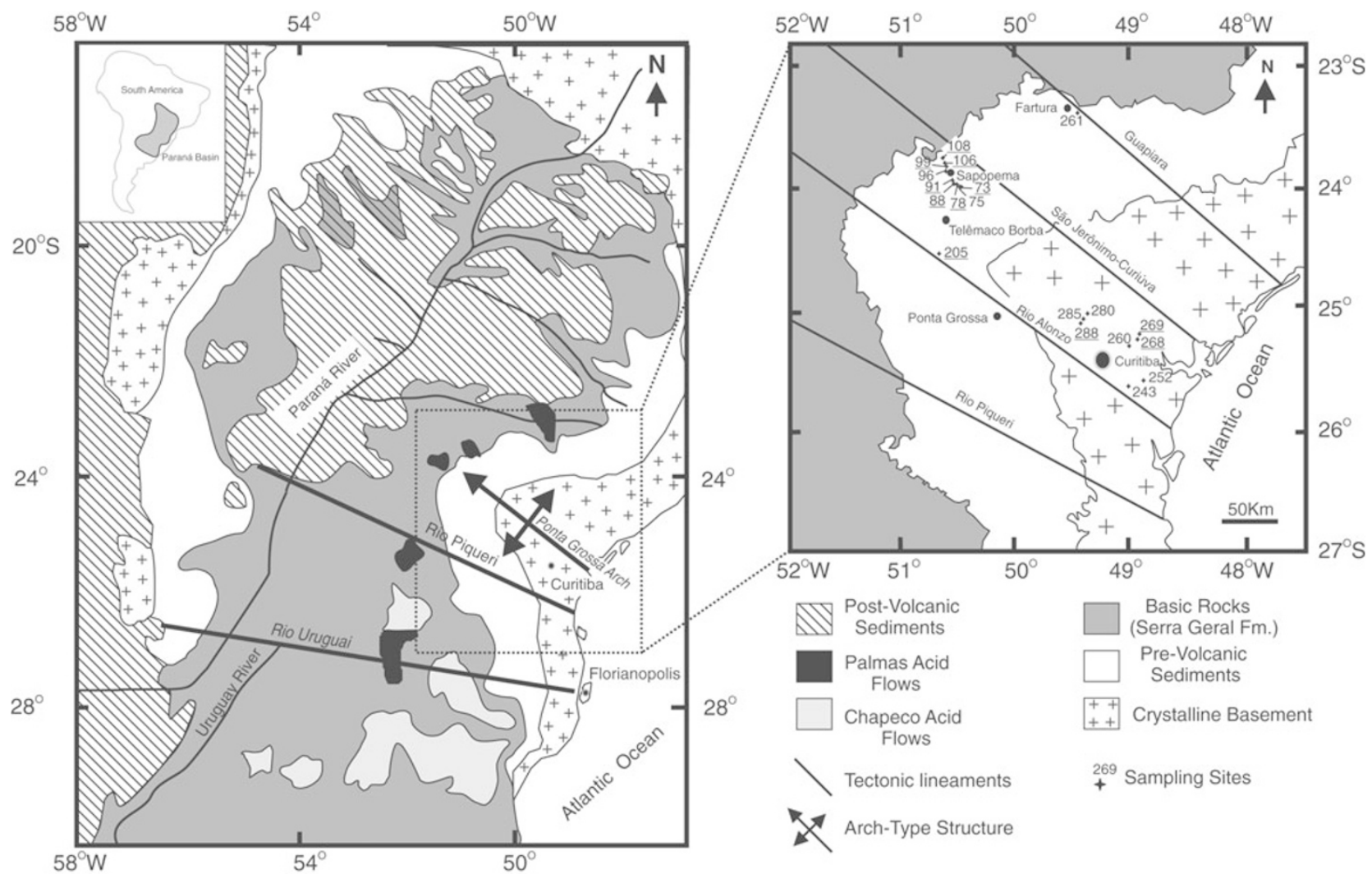

Fig. 1. Schematic geological map of the Paraná basin (left) and the Ponta Grossa Arch (right) indicating the paleomagnetic sites used in this study (modified from Raposo and Ernesto, 1995). Sites with reliable paleointensity estimates are underlined.

province is located in Brazil (mainly), Argentina, Paraguay, and Uruguay, but also extends to Africa. The PEMP magmatism occurred between 133 and 130 Ma (Renne et al., 1992, 1996). The tholeiitic basalt flows of the Serra Geral Formation represent the main pulse of the PEMP event, starting at $133 \pm 1 \mathrm{Ma}$ and lasting less than one million years (Renne et al., 1992). Fissural magmatism that crop outs around the basaltic traps at the present time is slightly younger, and comprises basaltic and andesitic dikes. Ages vary from 129 to 131 for the Ponta Grossa dikes (peak 130.5 Ma) (Renne et al., 1996) and range from 119 Ma to $128 \mathrm{Ma}$ in the Florianopolis dikes (Raposo et al., 1998).

Paleomagnetic studies were performed by several authors on Serra Geral volcanics and the dikes of Ponta Grossa and Florianopolis (e.g., Ernesto et al., 1990, 1999; Raposo and Ernesto, 1995; Raposo et al., 1998; Alva-Valdivia et al., 2003). All of these studies revealed very stable two-polarity characteristic magnetic components carried by titanomagnetite. Only two paleointensity studies have been reported for the Serra Geral volcanics (Kosterov et al., 1998; Goguichaitchvili et al., 2002). In both of these, double-heating techniques were used on samples from two different regions of the Paraná basin. Kosterov et al. (1998) obtained paleointensities between 20.8 and $37.7 \mu \mathrm{T}$ (virtual dipole moment (VDM) 4.7-7.9 × $10^{22} \mathrm{~A} \mathrm{~m}^{2}$ ), with a low success rate of $9 \%$ probably caused by a strong alteration during heating experiments. Goguichaitchvili et al. (2002) obtained a much better success rate of $44 \%$ and obtained paleointensity values with a large dispersion varying from 19.4 up to 46.7 $\mu \mathrm{T}\left(\mathrm{VDM} 4.0-10.5 \times 10^{22} \mathrm{~A} \mathrm{~m}^{2}\right)$.
Paleomagnetic results for the Ponta Grossa dikes resulted in an average direction of Dec $=351.7^{\circ}$ and $\mathrm{Inc}=-42.7^{\circ}$, which was obtained for both normal and reverse polarities (all rotated to the normal polarity). This direction corresponds to a paleomagnetic pole at $30.3^{\circ} \mathrm{E}, 82.4^{\circ} \mathrm{S}(N=$ $115, A_{95}=2.0^{\circ}, K=43.8$ ) (Raposo and Ernesto, 1995). The characteristic component was isolated after heating steps of $200^{\circ} \mathrm{C}$ to $450^{\circ} \mathrm{C}$ from stepwise thermal treatment. Titanomagnetite grains are usually well-preserved, with no evident sign of low-temperature oxidation in polished sections. Some samples, however, show non-reversible thermomagnetic curves that suggest some degree of alteration. The samples used in our study come from left-over hand-samples of Raposo and Ernesto's (1995) work. We have chosen sites with normal and reverse components and avoided sites with intermediate directions. For each site, all analyzed samples were cut from the same hand-sample.

\section{Thermal Stability}

Magnetic mineralogy and thermal stability were checked using thermomagnetic curves and by monitoring the magnetic susceptibility of samples before and after heating in a paleomagnetic oven. Measurements of magnetic susceptibility were performed in a KLY4-CS3 Kappabridge susceptometer (Agico Ltd.). Initially, a group of 68 samples (26 sites) was submitted to in-air heating up to $600^{\circ} \mathrm{C}$ in a paleomagnetic oven. Their magnetic susceptibility was measured before and after heating and found to vary from 0.8 to $152 \%$. Only 24 samples, representing 19 sites, presented less than $10 \%$ variation. Samples from these 19 

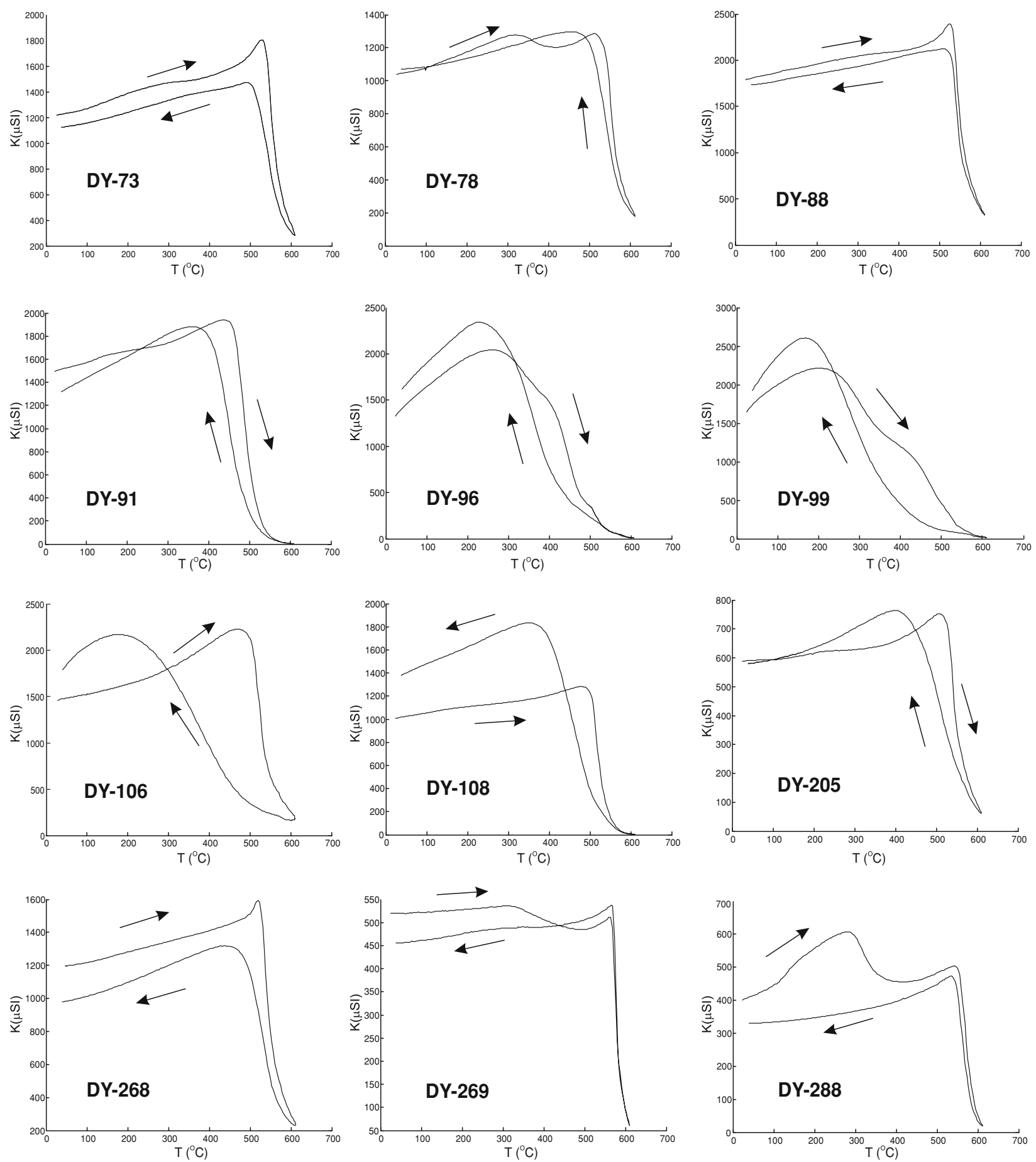

Fig. 2. Thermomagnetic curves for samples from all sites analyzed by the multisample paleointensity protocol.

sites were then selected for the analysis of thermomagnetic curves (Fig. 2). Thermomagnetic curves for all samples show a strong decay in magnetic susceptibility between $500^{\circ} \mathrm{C}$ and $580^{\circ} \mathrm{C}$, indicating that the main magnetic carrier in the basaltic dikes is magnetite with a low titanium content. These results are comparable to those obtained by Raposo and Ernesto (1995) from curves of saturation magnetization against temperature. For most of the samples, however, the thermomagnetic curves are non-reversible, even though their magnetic susceptibilities before and after heating are similar (Fig. 2). This behavior attests to the low thermochemical stability of the Ponta Grossa samples.

\section{Stepwise Double-heating Paleointensity}

From the 19 sites selected on the basis of thermomagnetic experiments, we selected four for classical stepwise doubleheating experiments (Thellier-Thellier method). Paleointensity measurements were performed using the Aitken et al. (1988) protocol with in-field preceding zero-field heatings. Repeatability was assessed by means of pTRM checks performed between two double-heating steps. For the paleointensity measurements, we used reduced cylindrical specimens of $0.65 \mathrm{~cm}^{3}$. Remanent magnetization was measured with a JR-6A (Agico Ltd.) magnetometer. Heating cycles of 40 min were applied in a modified MMTD-60 (Magnetic 

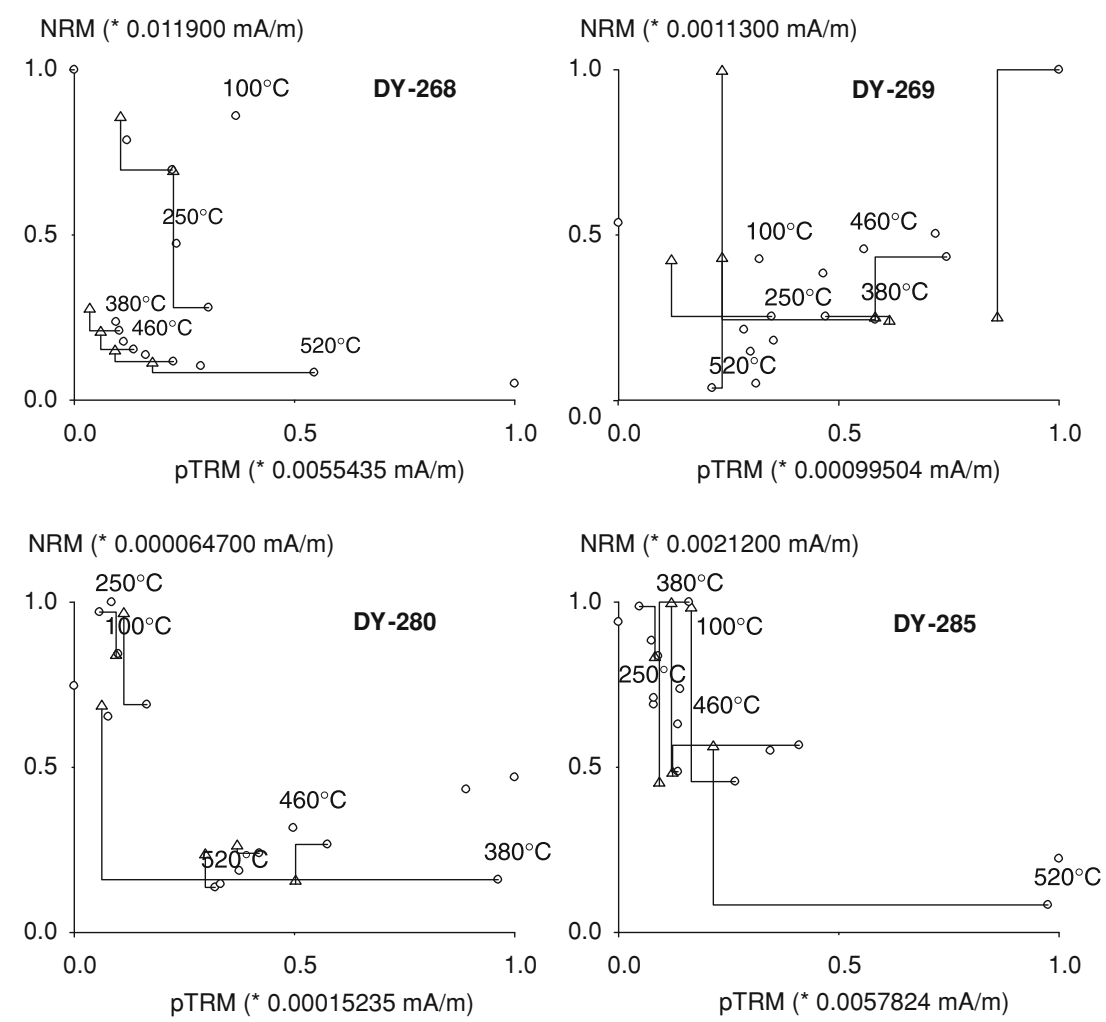

Fig. 3. Arai plots of selected samples from four sites. All samples show a strong scatter in double-heating results and failure of pTRM checks.

Measurements Ltd.) paleomagnetic oven, which includes a water-cooling system that guarantees a good temperature homogeneity in the heating chamber. Temperature and inducing field gradients were measured inside the chamber, and only the zone with more homogeneous temperature and field was used. In addition, samples were always located at the same position at all heating steps. During the experiments, all instruments and specimens were housed in a magnetically shielded room with an internal field below $1 \mu \mathrm{T}$.

The four sites investigated were found to show very scattered Arai plots, with failed pTRM checks (Fig. 3). Consequently, no information on the ancient magnetic field intensity could be gathered from these measurements. Given the failure of the pTRM checks and the non-reversible character of the thermomagnetic curves obtained on sister samples, we attribute this behavior to significant thermochemical alteration during the paleointensity experiments.

\section{Multisample Paleointensity}

Multisample paleointensity methods were developed by a number of researchers in an attempt to reduce measurement time while also reducing thermochemical alteration due to their very limited number of heatings per sample (Hoffman et al., 1989; Hoffman and Biggin, 2005; Dekkers and Böhnel, 2006). Multisample methods are based on the same principle of the Thellier-Thellier method to recover the ancient field, i.e. the fact that the acquired thermoremanence is linearly related to the inducing field (valid for low magnetic fields, in the range of the Earth's field). In practice, the multisample methods rely on the natural variations in magnetic properties at the scale of a paleomagnetic site to derive the linear relation between natural and artificial remanences. These may be determined by varying the peak temperature of heatings (e.g., Hoffman et al., 1989; Hoffman and Biggin, 2005) or by varying the inducing (laboratory) fields (e.g., Dekkers and Böhnel, 2006).

We used a multisample protocol in which different inducing fields were applied to several specimens of the same site, with only one in-field heating. This approach yields reliable paleointensity estimates regardless of the domain state of the magnetic carriers (Dekkers and Böhnel, 2006). We investigated only the 19 sites selected after thermomagnetic measurements.

We initially performed classical paleomagnetic demagnetization to derive the unblocking temperatures for the secondary component $\left(T_{\mathrm{sec}}\right)$ and the characteristic remanence $\left(T_{\mathrm{ch}}\right)$. One pilot sample per site was submitted to stepwise thermal demagnetization along 13 heating steps up to $580^{\circ} \mathrm{C}$ (Fig. 4). Demagnetization patterns for all samples but two revealed a very stable magnetization. The characteristic component (ChRM) was isolated after elimination of a secondary component (SecRM) at temperatures varying from $150^{\circ} \mathrm{C}$ up to $550^{\circ} \mathrm{C}$. The two samples with erratic behavior (Fig. 4(a, b)) and other five samples with very high-temperature secondary components were discarded. Multisample paleointensity measurements were then performed on the remaining 12 sites.

Multisample paleointensity estimates were performed for seven samples from each site using three heating steps: (1) a zero-field heating up to $T_{\mathrm{sec}}$, (2) an in-field heating up to $T_{\mathrm{ch}}$, and (3) a zero-field heating up to $T_{\mathrm{sec}}$. The remanence obtained after heating step (1) is the ChRM, and the remanence obtained after heating step (3) is the laboratory- 
A DY75

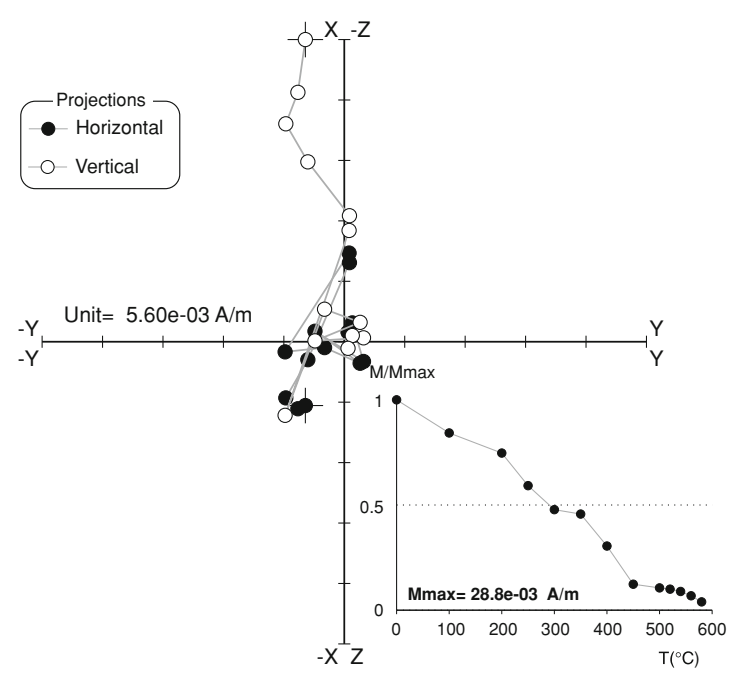

(C) DY73

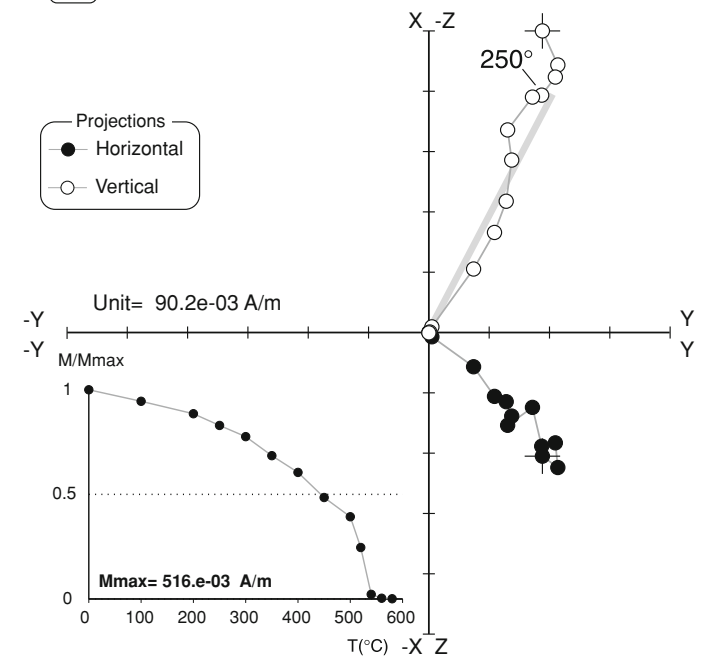

E DY108

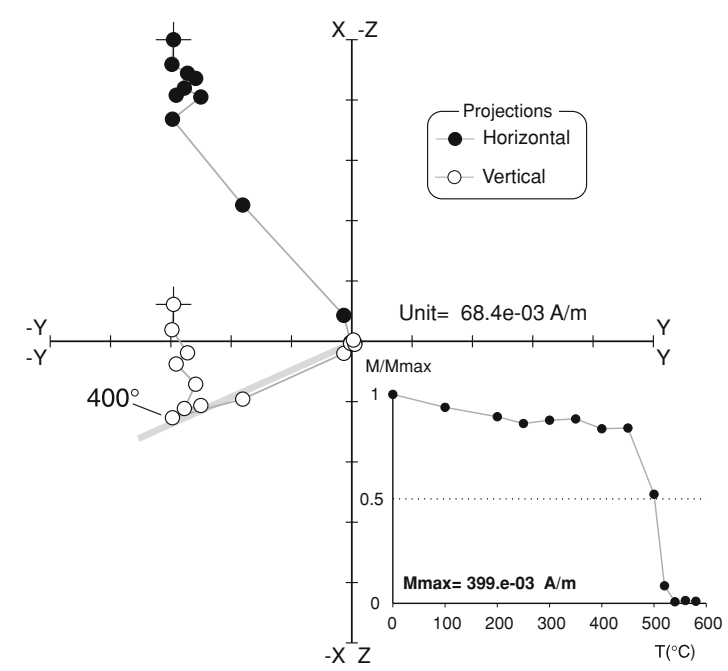

B DY260

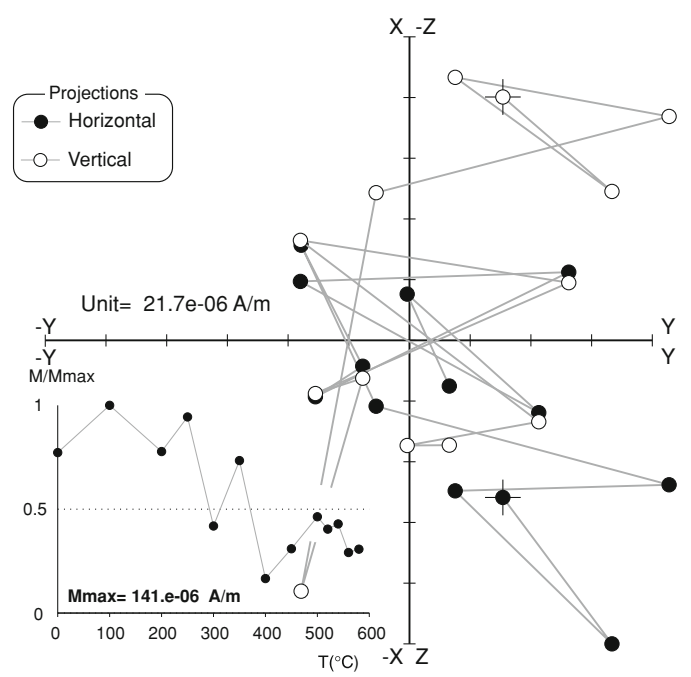

D DY288

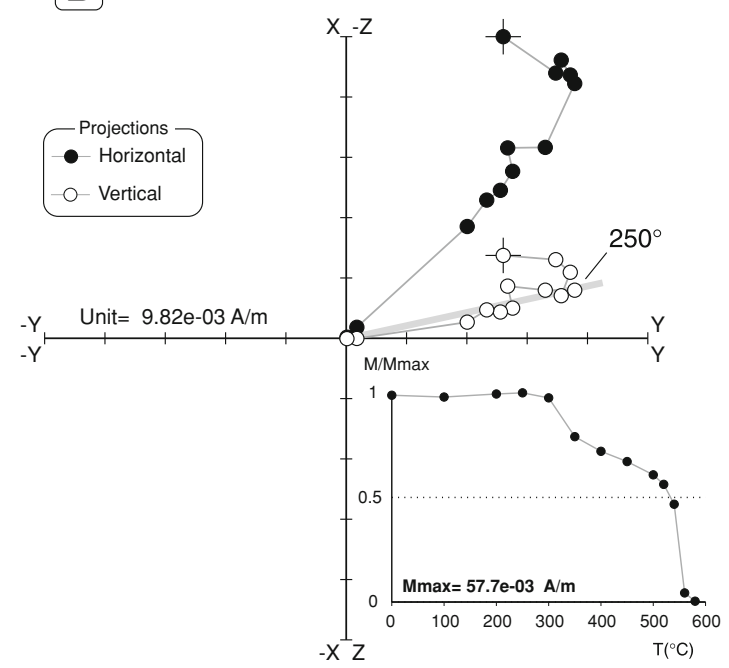

F DY88

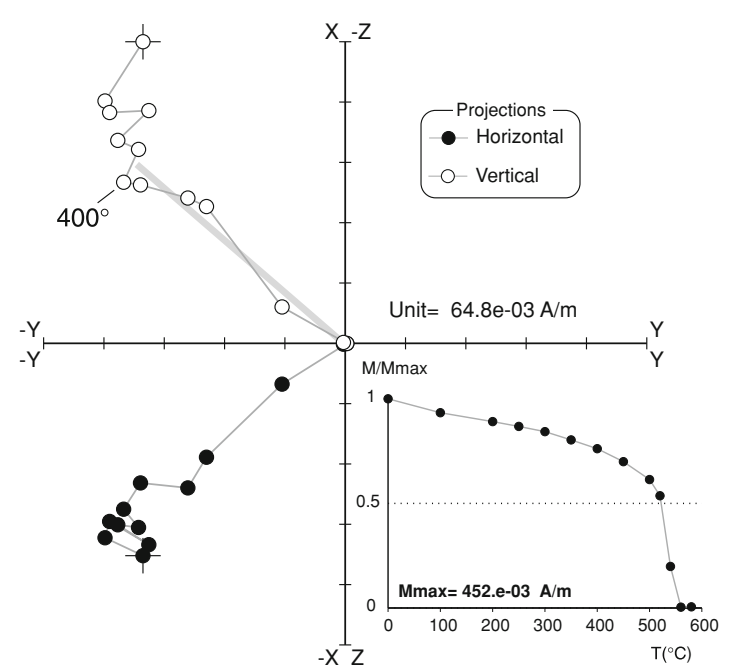

Fig. 4. Thermal demagnetization of six representative samples represented by intensity decay and orthogonal diagrams (in specimen coordinates). The characteristic component (ChRM) for each sample is indicated in the orthogonal diagrams by a thick grey line. The unblocking temperature of the secondary component is also indicated. 


\section{Characteristic - Total + pTRM Check $\Delta$}
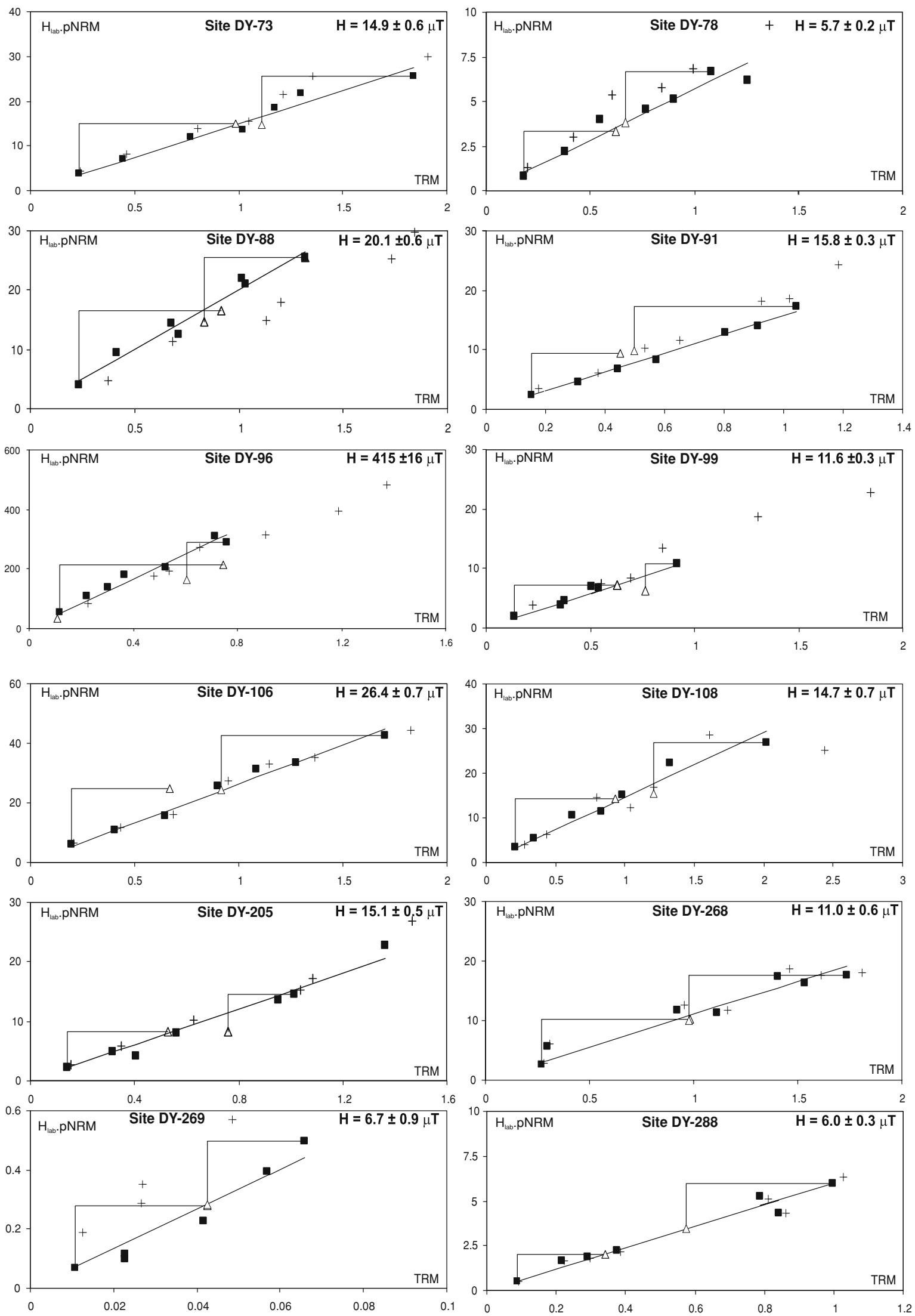

Fig. 5. NRM. $H_{\text {lab }}$-TRM plots (Arai-like) for 12 sites. The product of $H_{\text {lab }}$ and pNRM is given against the corresponding pTRM for seven samples. For each site, we show the results obtained for the ChRM (full squares) and the total vector (crosses). The line corresponds to the fitting of the ChRM data. Empty triangles show pTRM checks. 
Table 1. Multisample paleointensity results.

\begin{tabular}{|c|c|c|c|c|c|c|c|c|c|}
\hline Site & Lat $\left(^{\circ}\right)$ & Lon $\left(^{\circ}\right)$ & $\operatorname{Dec}\left(^{\circ}\right)$ & $\operatorname{Inc}\left({ }^{\circ}\right)$ & $A_{95}\left(^{\circ}\right)$ & $H(\mu \mathrm{T})$ & $\sigma_{\mathrm{H}}$ & $\operatorname{VDM}\left(10^{22} \mathrm{~A} \mathrm{~m}^{2}\right)$ & $\sigma_{\mathrm{VDM}}$ \\
\hline DY-73 & -24.03 & -50.47 & 349.4 & -37.8 & 2.6 & 14.9 & 0.6 & 3.3 & 0.12 \\
\hline DY-78 & -24.00 & -50.49 & 344.6 & -36.3 & 4.8 & 5.7 & 0.2 & 1.3 & 0.04 \\
\hline DY-88 & -23.95 & -50.54 & 353.8 & -42.7 & 1.8 & 20.1 & 0.6 & 4.2 & 0.13 \\
\hline DY-91 & -23.94 & -50.56 & 5.9 & -31.4 & 2.3 & 15.8 & 0.3 & 3.7 & 0.07 \\
\hline DY-99 & -23.86 & -50.62 & 350.5 & -29.1 & 2.8 & 11.6 & 0.3 & 2.7 & 0.08 \\
\hline DY-106 & -23.83 & -50.62 & 352.2 & -33.4 & 4.6 & 26.4 & 0.7 & 6.0 & 0.17 \\
\hline DY-108 & -23.80 & -50.70 & 339.2 & -28.0 & 8.1 & 14.7 & 0.7 & 3.5 & 0.17 \\
\hline DY-205 & -24.56 & -50.50 & 161.9 & 45.4 & 1.8 & 15.1 & 0.5 & 3.1 & 0.10 \\
\hline DY-268 & -25.19 & -48.81 & 354.4 & -58.0 & 3.9 & 11.0 & 0.6 & 1.9 & 0.10 \\
\hline DY-269 & -25.22 & -48.87 & 171.2 & 45.0 & 4.5 & 6.7 & 0.9 & 1.4 & 0.18 \\
\hline DY-288 & -25.09 & -49.46 & 180.4 & 37.3 & 1.9 & 6.0 & 0.3 & 1.3 & 0.06 \\
\hline Mean & & & & & & 13.4 & 1.9 & 2.9 & 0.4 \\
\hline$D Y-96$ & -23.88 & -50.62 & 10.2 & -26.5 & 5 & 415 & 16 & 99 & 4 \\
\hline
\end{tabular}

Lat: latitude, Lon: longitude, Dec: declination of characteristic component, Inc: inclination of characteristic component, $A_{95}$ : confidence angle from Fisherian statistics, $H$ and $\sigma_{\mathrm{H}}$ : paleofield and error, VDM and $\sigma_{\mathrm{VDM}}$ : virtual dipole moment and error. Site DY-96 was not included in the mean.

Table 2. Alteration parameters for samples S10-S70 (number corresponds to the inducing field in $\mu \mathrm{T}$ ).

\begin{tabular}{|c|c|c|c|c|c|c|c|c|c|}
\hline \multirow{2}{*}{ Site } & \multicolumn{7}{|c|}{$\Delta k(\%)$} & \multicolumn{2}{|c|}{ pTRM check $(\delta \%)$} \\
\hline & $\mathrm{S} 10$ & $\mathrm{~S} 20$ & S30 & S40 & S50 & S60 & S70 & S10 & S70 \\
\hline DY-73 & -9 & -12 & -14 & -11 & -14 & -15 & -12 & -6 & -6 \\
\hline DY-78 & -12 & -10 & -11 & -11 & -11 & -19 & -9 & 13 & 7 \\
\hline DY-88 & -15 & -15 & -14 & -14 & -11 & -13 & -28 & 0 & -11 \\
\hline DY-91 & -21 & -27 & -20 & -13 & -34 & -32 & -30 & 25 & 17 \\
\hline$D Y-96$ & -9 & -30 & -2 & -16 & 25 & -16 & 0 & -60 & -40 \\
\hline DY-99 & -12 & -5 & -15 & -6 & -18 & -5 & -8 & -16 & -6 \\
\hline DY-106 & -1 & 7 & -2 & 1 & -1 & -2 & -2 & -15 & -6 \\
\hline DY-108 & 24 & 22 & 19 & 20 & 19 & 19 & 20 & -9 & -5 \\
\hline DY-205 & 6 & 3 & 25 & 14 & 2 & 2 & -1 & 7 & 3 \\
\hline DY-268 & -25 & 4 & -26 & -25 & -25 & -26 & -25 & 8 & 2 \\
\hline DY-269 & -15 & -14 & -13 & -11 & -12 & -14 & -15 & 2 & -13 \\
\hline DY-288 & -2 & -10 & 2 & -8 & -4 & -9 & -10 & 4 & -1 \\
\hline
\end{tabular}

induced pTRM. Each sample was magnetized with a different laboratory inducing field $\left(H_{\mathrm{lab}}\right.$ values: $10,20,30,40$, 50, 60, and $70 \mu \mathrm{T}$ ). Paleointensity values were calculated using an Arai-like plot (Fig. 5). In this diagram, we plot the product of the ChRM and $H_{\text {lab }}$ for each sample against the corresponding pTRM. Since ChRM. $H_{\mathrm{lab}}=$ pTRM. $H_{\mathrm{a}}$, the ancient field $\left(H_{\mathrm{a}}\right)$ can be easily obtained from the slope of the line. To obtain this slope, we used the same leastsquare fitting routines used in classical double-heating protocols (e.g., York, 1966). Uncertainties correspond to the error on the best fit line. Note that each point in the Arailike plot corresponds to an individual estimate of paleointensity; their alignment in a given site attests to within-site coherence of paleointensity estimates.

The paleointensity results are shown in Fig. 5 and Table 1. For all sites, the seven analyzed samples present a very good alignment in the Arai-like plots, indicating a strong coherence of paleointensity estimates within each site. For 11 sites, the paleointensity estimates vary between $5.7 \pm 0.2$ and $26.4 \pm 0.7 \mu \mathrm{T}$. Site DY-96 presented an anomalously (and implausibly) high value of $415 \pm 16 \mu \mathrm{T}$. It is interesting to note that the paleointensities obtained from the characteristic magnetization are similar to the apparent paleointensities calculated from the total remanence vector (compare the alignment of squares and crosses in Fig. 5). For most of the sites, these differences are well below 10\%, indicating that even if the secondary components were not completely eliminated they would contribute little to the final paleointensity estimates. Virtual dipole moments were calculated using the inclination of the characteristic component for each site obtained from the original paleomagnetic study of Raposo and Ernesto (1995). These correspond to VDM values of $1.3 \pm 0.04$ to $6.0 \pm 0.2 \times 10^{22} \mathrm{~A} \mathrm{~m}^{2}$ (average of $2.9 \pm 0.5 \times 10^{22} \mathrm{~A} \mathrm{~m}^{2}$ ) (Table 1).

The thermochemical alteration during paleointensity measurements was monitored by magnetic susceptibility measurements and a pTRM check (Table 2). Magnetic susceptibility was measured before heating step (1) and after heating step (3). The percentual difference between the two measurements is $\Delta k(\%)$. The pTRM check envisaged here consists of a new in-field heating cycle in a different $H_{\text {lab }}$ (or $H_{\text {check }}$ ) performed after the paleointensity measurement. The aim of this test is to verify that the capacity of the sample in recording a thermoremanence does not change through the two heating steps. This can be quantified by a $\delta$ parameter that corresponds to the percentual difference 
between the TRM $/ H_{\text {lab }}$ ratio of the first in-field heating and the TRM $/ H_{\text {lab }}$ ratio of the pTRM check:

$$
\delta=H_{\mathrm{lab}} \frac{\left(\frac{\mathrm{pTRM}_{\text {check }}}{H_{\text {check }}}-\frac{\mathrm{pTRM}_{1}}{H_{\text {lab }}}\right)}{\mathrm{pTRM}_{1}} .
$$

Unaltered samples would present low $\delta$ values.

The values of $\Delta k$ vary from -34 up to $+25 \%$ and values for $\delta$ vary from -60 up to $+25 \%$ (Table 2 ). Site DY96, which gives anomalously high paleointensity values, presents the highest variations in both parameters. At this site, $\Delta k$ varies between $-30 \%$ and $+25 \%$, and $\delta$ values are -40 and $-60 \%$. The other sites that give coherent paleointensity estimates show less variation in $\Delta k$ values and much smaller $\delta$ values. These results suggest that these parameters can be used to assess the quality of paleointensity determinations in multisample methods. However, both parameters have a number of drawbacks. The $\Delta k$ parameter indicates only the variation in initial and final magnetic susceptibilities. As shown in the thermomagnetic curves of Fig. 2, samples may experience thermomagnetic alteration albeit showing similar initial and final magnetic susceptibilities. The $\delta$ parameter indicates only the alteration that occurs after the first in-field heating cycle, i.e., after the paleointensity determination.

\section{Discussion and Conclusion}

The multisample protocol has proven to be useful for determining paleointensities for the Ponta Grossa dikes that were not suitable for double-heating techniques. The within-site consistency of thermoremanence acquisition was asserted by the analysis of mean-square fit parameters. A pTRM check was devised to account for mineralogical alteration during heating. Most of the sites have provided coherent paleointensity estimates, indicating low to moderate paleofields with a mean at $13.4 \pm 1.9 \mu \mathrm{T}$ (VDM $2.9 \pm$ $\left.0.5 \times 10^{22} \mathrm{~A} \mathrm{~m}^{2}\right)$. Samples with normal and reverse polarities gave similar paleofield estimates (Table 1).

Figure 6 shows the dipole moment values from the five Ponta Grossa dikes together with VDMs and virtual axial dipole moments (VADMs) from other units with ages between 80 and $167 \mathrm{Ma}$. This compilation includes only results obtained from double-heating techniques with pTRM checks and originate from the following sources: data from whole rock were obtained from the PINT2003 database of Perrin and Schnepp (2004) supplemented with results from Ruiz et al. (2006) and Granot et al. (2007); data from oceanic basaltic glass correspond to the database of Tauxe (2006), and data from single silicate crystals were compiled from Tarduno et al. (2001) and Tarduno and Cottrell (2005).

The paleointensity data between 80 and $160 \mathrm{Ma}$ are sparsely distributed with very few data at the middle of the Cretaceous Normal Superchron (CNS). Intervals of 80$95 \mathrm{Ma}$ and 115-135 Ma show the highest density of results. Within these intervals, there is a strong variability of VDM values, but the highest dipole moments are located within the CNS. This pattern, initially observed on single silicate crystals (Tarduno et al., 2001), is also observed on basaltic glasses. Results from whole-rock analyses, however, show a stronger variability, with both high

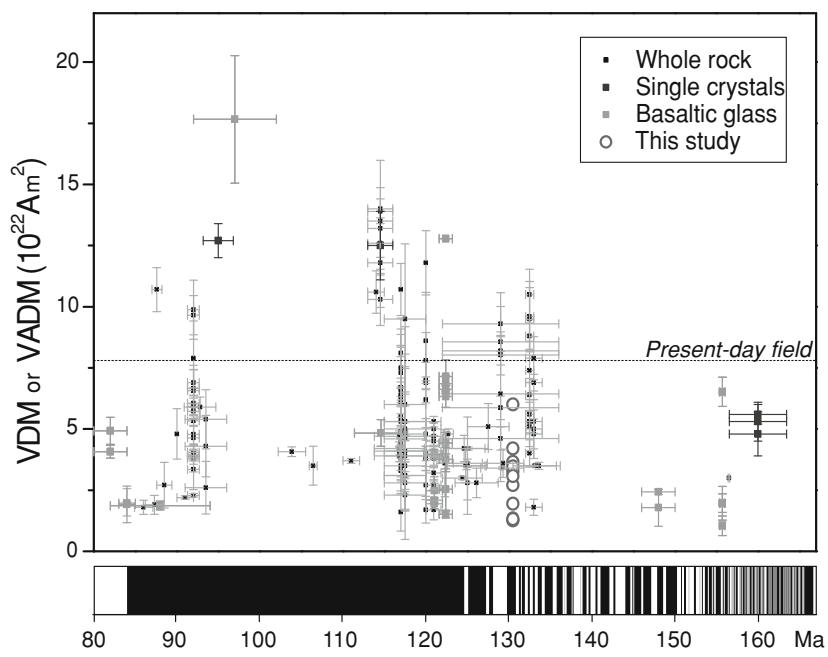

Fig. 6. Evolution of virtual dipole moments (VDM) or virtual axial dipole moments (VADM) for cooling units (single-silicate crystals and whole-rock) and individual specimens (oceanic basaltic glass) with ages between 80 and $167 \mathrm{Ma}$. Black squares correspond to whole rock data (Riisager et al., 2001; Perrin and Schnepp, 2004; Zhu et al., 2004a, b, c; Shi et al., 2005), blue empty squares correspond to single silicate crystals (Tarduno et al., 2001; Tarduno and Cottrell, 2005), green empty squares correspond to oceanic basaltic glass (Tauxe, 2006), and red circles are our data. Reversal chart is from Gradstein et al. (2004).

and low values within the CNS. Before the CNS, the paleointensity data show a strong variability for all datasets, but average dipole moments are dominantly low. The average dipole between the end of the CNS and the middle Jurassic is $4.7 \times 10^{22} \mathrm{~A} \mathrm{~m}^{2}$. All results from the upper and middle Jurassic fall below the present-day dipole moment of $7.8 \times 10^{22} \mathrm{~A} \mathrm{~m}^{2}$. For ages closer to the lower CNS boundary, higher values were observed in two studies with mean VDMs of approximately $7 \times 10^{22} \mathrm{~A} \mathrm{~m}^{2}$ similar to the present-day field (Goguitchaichvili et al., 2002; Ruiz et al., 2006). However, other studies give systematically low dipole moments. Results from volcanics from northeast China (Zhu et al., 2003, 2004a, b) and also the data from the Serra Geral volcanics of Kosterov et al. (1998) are always below the present-day field with an average value of $3.6 \times 10^{22} \mathrm{~A} \mathrm{~m}^{2}$. Our results (average of $2.9 \times 10^{22} \mathrm{~m}^{2}$ ) agree with such a tendency for low dipole moments in the Early Cretaceous, just before the CNS. In summary, there seems to be a strong variability of the field throughout the time-window of our analysis. At present, there is no firm evidence for a MDL, but a long-term tendency does emerge from the data, with highest dipole moments occurring at the middle of the CNS.

Acknowledgments. Financial support for this work comes from Brazilian agencies CNPq and FAPESP (grant 05/57782-4). We thank M. Ernesto by suggesting the use of the Ponta Grossa dikes collection in this paleointensity study. Constructive reviews by Mimi Hill and Aleksey Smirnov led to significant improvement of the paper.

\section{References}

Aitken, M. J., A. L. Allsop, G. D. Bussell, and M. B. Winter, Determination of the intensity of the Earth's magnetic field during archaeological times: Reability of the Thellier technique, Rev. Geophys., 26, 3-12, 1988. 
Alva-Valdivia, L. M., A. Goguitchaichvili, J. Urrutia-Fucugauchi, J. Riisager, P. Riisager, and O. Ferreira-Lopes, Paleomagnetic poles and paleosecularvariation of basalts from Parana Magmatic Province, Brazil: geomagnetic and geodynamic implications, Phys. Earth Planet. Inter., 138, 183-196, 2003.

Biggin, A. J. and D. N. Thomas, Does the Mesozoic Dipole Low Really Exist?, Eos, 84(11), 97, 103-104, 2003.

Coe, R. S., S. Grommé, and E. A. Mankinen, Geomagnetic paleointensities from radiocarbon-dated lava flows on Hawaii and the question of the Pacific nondipole low, J. Geophys. Res., 83, 1740-1756, 1978.

Dekkers, M. J. and H. N. Böhnel, Reliable absolute palaeointensities independent of magnetic domain state, Earth Planet. Sci. Lett., 248(1-2), 508-517, 2006.

Ernesto, M., I. G. Pacca, F. Y. Hiodo, and A. J. R. Nardy, Palaeomagnetism of the Mesozoic Serra Geral Formation, Southern Brazil, Phys. Earth Planet. Inter., 64, 153-175, 1990.

Ernesto, M., M. I. B. Raposo, L. S. Marques, P. R. Renne, L. A. Diogo, and A. De Min, Paleomagnetism, geochemistry and 40Ar/39Ar dating of the North-eastern Paraná Magmatic Province: tectonic implications, J. Geodyn., 28, 321-340, 1999.

Goguitchaichvili, A., L. Alva-Valdivia, J. Urrutia-Fucugauchi, J. Morales, and O. Ferreira-Lopes, On the reliability of Mesozoic dipole low: new absolute paleointensity results from Paraná flood basalts (Brazil), Geophys. Res. Lett., 29(13), 1655, 2002.

Gradstein, F., J. Ogg, and A. Smith, A Geologic Time Scale 2004, 589 pp., Cambridge Univ. Press, New York, 2004.

Granot, R., L. Tauxe, J., J. S. Gee, and R. Hagai, A view into the Cretaceous geomagnetic field analysis of gabbros and submarine glasses, Earth Planet. Sci. Lett., 256, 1-11, 2007.

Heller, R., R. T. Merrill, and P. L. McFadden, The variation of intensity of earth's magnetic field with time, Phys. Earth Planet. Inter., 131(3-4), 237-249, 2002.

Hoffman, K. A. and A. J. Biggin, A rapid multiple-sample approach to the determination of absolute paleointensity, J. Geophys. Res., 110(B12), 2005.

Hoffman, K. A., V. L. Constantine, and D. L. Morse, Determination of absolute palaeointensity using a multi-specimen procedure, Nature, 339, 295-297, 1989.

Kosterov, A., M. Perrin, J. M. Glen, and R. S. Coe, Paleointensity of the earth's magnetic field in early Cretaceous time: the Paraná basalt, Brazil, J. Geophys. Res., 103, 9739-9753, 1998.

Perrin, M. and E. Schnepp, IAGA paleointensity database: distribution and quality of the data set, Phys. Earth Planet. Inter., 147, 255-267, 2004.

Prévot, M., M. E. M. Derder, M. McWilliams, and J. Thompson, Intensity of the Earth's magnetic field: evidence for a Mesozoic dipole low, Earth Planet. Sci. Lett., 97, 129-139, 1990.

Raposo, M. I. B. and M. Ernesto, An Early Cretaceous paleomagnetic pole from Ponta Grossa dykes (Brazil): implications for the South America Mesozoic APWP, J. Geophys. Res., 100(B10), 20095-20109, 1995.

Raposo, M. I. B., M. Ernesto, and P. R. Renne, Paleomagnetism and 40Ar/39Ar dating of the Florianópolis dike swarm, Santa Catarina Island, Brazil, Phys. Earth Planet. Inter., 108, 275-290, 1998.

Renne, P. R., M. Ernesto, I. G. Pacca, R. S. Coe, J. Glen, M. Prévot, and M. Perrin, Rapid eruption of the Paraná food volcanics, rifting of southern Gondwanaland and the Jurassic-Cretaceous boundary, Science, 258, 975-979, 1992.

Renne, P. R., K. Deckart, M. Ernesto, G. Fearaud, and E. M. Piccirillo, Age of the Ponta Grossa dike swarm (Brazil), and implications to Paraná food volcanism, Earth Planet. Sci. Lett., 144, 199-211, 1996.

Riisager, P. and J. Riisager, Detecting multidomain magnetic grains in Thellier palaeointensity experiments, Phys. Earth Planet. Inter., 125(14), 111-117, 2001.

Riisager, J., M. Perrin, R. Riisager, and D. Vandamme, Paleomagnetic results and palaeointensity of Late Cretaceous Madagascan basalt, $J$. Afr. Earth Sci., 32, 503-518, 2001.

Ruiz, R. C., A. Goguitchaichvili, S. E. Geuna, L. M. Alva-Valdivia, J. Solé, and J. Morales, Early Cretaceous absolute geomagnetic paleointensities from Córdoba Province (Argentina), Earth Planets Space, 58, 1333 1339, 2006.

Selkin, P. and L. Tauxe, Long-term variations in paleointensity, Philos. Trans. Roy. Soc. Lond., 358, 1065-1088, 2000.

Shi, R., M. J. Hill, R. Zhu, H. He, and J. Shaw, Paleointensity determination and ${ }^{40} \mathrm{Ar} /{ }^{39} \mathrm{Ar}$ dating on the basalt from Chifeng, Inner Mongolia, Phys. Earth Planet. Inter., 152, 78-89, 2005.

Tarduno, J. A. and R. D. Cottrell, Dipole strength and variation of the timeaveraged reversing and non-reversing geodynamo based on Thellier analyses of single plagioclase crystals, J. Geophys. Res., 110(B11), 101, 2005.

Tarduno, J. A., R. D. Cottrell, and A. V. Smirnov, High geomagnetic intensity during the Mid-Cretaceous from Thellier analyses of single plagioclase crystals, Science, 291, 1779-1783, 2001.

Tarduno, J. A., R. D. Cottrell, and A. V. Smirnov, The paleomagnetism of single silicate crystals: recording geomagnetic field strength during mixed polarity intervals, superchrons, and inner core growth, Rev. Geophys., 41, RG1002, 2006.

Tauxe, L., Long-term trends in paleointensity: the contribution of DSDP/ODP submarine basaltic glass collections, Phys. Earth Planet. Inter., 156, 223-241, 2006.

Tauxe, L. and H. Staudigel, Strength of the geomagnetic field in the Cretaceous Normal Superchron: new data from submarine basaltic glass of the Troodos Ophiolite, Geochem. Geophys. Geosyst., 5(2), Q02H06, 2004.

Thellier, E. and O. Thellier, Sur l'intensité du champ magnetiqué terrestre dans le passé historique et géologique, Ann. Geophys., 15, 285-376, 1959.

York, D., Least-square fitting of a straight line, Can. J. Phys., 44, 1079_ 1086, 1966

Zhu, R., K. Hoffman, Y. Pan, R. Shi, and L. Daming, Evidence for weak geomagnetic intensity prior to the Cretaceous normal subchron, Phys. Earth Planet. Inter., 136, 187-199, 2003.

Zhu, R. X., K. A. Hoffman, S. Nomade, P. R. Renne, R. P. Shi, Y. X. Pan, and G. H. Shi, Geomagnetic paleointensity and direct age determination of the ISEA (M0r?) chron, Earth Planet. Sci. Lett., 217, 285-295, 2004a.

Zhu, R. X., C.-H. Lo, R. P. Shi, G. H. Shi, Y. X. Pan, and J. A. Shao, Palaeointensities determined from the middle Cretaceous basalt in Liaoning province, northeastern China, Phys. Earth Planet. Inter., 142, 49-59, 2004b.

Zhu, R. X., C. Lo, R. Shi, Y. Pan, G. Shi, and J. Shi, Is there a precursor to the Cretaceous normal superchron? New paleointensity and age determination from Liaoning province, northeastern China, Phys. Earth Planet. Inter., 147, 117-126, 2004c.

D. Brandt (e-mail: daniele@iag.usp.br), G. A. Hartmann, E. Yokoyama, E. L. Catelani, and R. I. F. Trindade 